\title{
REPRESENTAÇÃO MENTAL DAS RELAÇÕES DE APEGO DE UM INDIVÍDUO DIAGNOSTICADO COM TRANSTORNO DEPRESSIVO MAIOR*
}

\author{
MENTAL REPRESENTATION OF ATTACHMENT \\ RELATIONSHIPS IN AN INDIVIDUAL DIAGNOSED \\ WITH MAJOR DEPRESSIVE DISORDER
}

\author{
Celina Monteiro AZEVEDO ${ }^{1}$ \\ Lília Nazaré de Souza NASCIMENTO² \\ Marco Aurélio Valle de MORAES ${ }^{3}$ \\ Airle Miranda de SOUZA ${ }^{4}$
}

\begin{abstract}
RESUMO
Este trabalho objetivou avaliar a representação mental das relações de apego de um indivíduo diagnosticado com Transtorno Depressivo Maior. Estudos anteriores sugerem ligação entre relações de apego estabelecidas no grupo familiar e modelos patológicos de funcionamento. Realizou-se um estudo de caso com um paciente do sexo feminino que apresentava o referido transtorno, atendida no Ambulatório de Ansiedade e Depressão do Hospital Universitário Bettina Ferro de Souza. Foram realizadas oito (08) entrevistas domiciliares. Utilizaram-se os seguintes instrumentos: a) Roteiro de Entrevista; b) Desenho da Família; c) Escala de Freqüência de Sinais Específicos; e d) Escala Global. Os resultados sugeriram o estabelecimento de relações de apego ansioso e evitante, revelando uma patologia global muito alta. Portanto, destacamos a importância de um ambiente familiar que ofereça atenção e cuidados a seus membros, propiciando segurança e favorecendo saúde biopsicossocial.
\end{abstract}

Palavras-chave: Representação Mental, Relações de Apego, Família e Depressão.

(*) Trabalho financiado pelo Conselho Nacional de Pesquisa - CNPq.

(1) Bolsista PIBIC/CNPq, estagiária do Projeto de Pesquisa "Instituição, Família e Saúde Mental", graduanda do Curso de Psicologia da Universidade Federal do Pará/UFPa.

(2) Bolsista PIBIC/CNPq, estagiária do Projeto de Pesquisa "Instituição, Família e Saúde Mental", graduanda do Curso de Psicologia da Universidade Federal do Pará/UFPa.

(3) Médico Psiquiatra, Prof. adjunto do Departamento de Psicologia Clínica da UFPa.

(4) Doutora em Saúde Mental-UNICAMP, Profa. adjunto do Departamento de Psicologia Social e Escolar da UFPa, Coordenadora do Projeto de Pesquisa "Instituição, Família e Saúde Mental".

Endereço para correspondência:Profa. Dra. Airle Miranda de Souza: Passagem Severa Romana, No 14, CEP: 66.120-370, Belém/ Pará, fone: (091) 244-9191. e-mail: ams@amazon.com.br 


\begin{abstract}
The objective of this work was to evaluate the mental representation of attachment relationships in an individual diagnosed with Major Depressive Disorder. Previous studies suggested a connection between the attachment relationships established in the familial group and pathological functioning models. A case study was performed with a female patient presenting the disorder, who was attended at Ambulatório de Ansiedade e Depressão of Hospital Universitário Betina Ferro de Souza. Eight domiciliary interviews were carried out. The following instruments were used: a) Interview Script; b) Drawing of the Family; c) Family Drawing Checklist of Signs; e d) Family Drawing Global Rating Scales. The results suggested the establishment of anxious and hesitating attachment relationships, revealing a very high global pathology. We stress, therefore, the importance of a familial environment which would offer attention and care to its members, providing safety and favoring biopsychosocial health.
\end{abstract}

Key words: Mental Representation, Attachment Relationships, Family, Depression.

\section{INTRODUÇÃO}

Ocomportamento de apegoé compreendido como qualquer forma de comportamento que permita a uma pessoa alcançar e manter proximidade com outro indivíduo claramente identificado, o qual é considerado mais apto a lidar com o mundo. A principal variável, no desenvolvimento da personalidade de cada indivíduo, é o caminho ao longo do qual seu comportamento de apego se organizou, e esse é influenciado pela maneira que suas figuras parentais (ou substitutos) o trataram, não só durante o início de sua vida, mas durante a infância e a adolescência. A maneira como uma pessoa interpreta o mundo a sua volta e como espera que as pessoas a quem deveria se apegar se comportem são derivativos dos modelos representacionais de seus pais, formados durante a infância (Bowlby, 1989).

Bowlby (1989) descreveu três modelos principais de apego e as condições familiares que os promoviam: 1) Apego Seguro: o indivíduo está confiante de que seus pais (ou substitutos) estarão disponíveis, oferecendo ajuda. A partir dessa base segura, sente-se corajoso para explorar o mundo; 2) Apego Resistente e
Ansioso: o indivíduo se mostra incerto quanto à disponibilidade de seus pais (ou substitutos) para oferecer ajuda, caso necessite. Por causa dessa incerteza, tende a ficar ansioso para explorar o mundo; 3) Apego Ansioso com Evitação: o indivíduo não tem nenhuma confiança de que receberá ajuda, ao contrário, espera ser rejeitado. Desse modo, procura viver sua vida sem amor e sem a ajuda de outros.

Cecconello \& Koller (1999) destacam que as experiências de apego desenvolvidas entre crianças e seus pais (ou substitutos) funcionam como um modelo para os próximos relacionamentos. Este processo é denominado, por Bowlby (1989), modelo interno de funcionamento, no qual a criança constrói uma imagem de si mesma e de seus pais, que governará o que ela sente em relação a ambos. O modelo interno de funcionamento, desenvolvido durante a primeira infância, evolui, passando a fazer parte da sua personalidade, transformando-se em uma representação mental da relação de apego, que tende a persistir durante toda a vida.

Cecconello et al. (2000) destacam que a representação mental de uma relação de apego segura proporciona o desenvolvimento de características pessoais importantes, tais como 
a empatia, auto-estima e competência pessoal. Dessa forma, as primeiras relações entre a criança e seus cuidadores constituem-se fontes potenciais de proteção, as quais podem minimizar os efeitos das adversidades e favorecer a resistência.

Bowlby (1989) ressalta que o comportamento de apego é claramente observado na primeira infância; contudo, ele pode ser observado durante todo o ciclo de vida, especialmente em situações de emergência, como no caso do indivíduo que apresenta depressão.

O Transtorno Depressivo Maior, de acordo com o Manual Diagnóstico e Estatístico de Transtornos Mentais (DSM-IV, 1995), é caracterizado por um período mínimo de duas semanas, durante as quais há um humor deprimido ou perda de interesse ou prazer por quase todas as atividades. O indivíduo experimenta outros sintomas, tais como: alterações no apetite ou peso, sono e atividade psicomotora, diminuição de energia, sentimentos de desvalia ou culpa, dificuldades para pensar, concentrarse ou tomar decisões, ou pensamentos recorrentes sobre morte ou ideação suicida, planos ou tentativas de suicídio.

O presente trabalho visou identificar, descrever e avaliar a representação mental da relação de apego, utilizando a técnica projetiva gráfica do desenho da família. Anzieu (1978) destaca que as técnicas projetivas tornaram-se valiosos instrumentos em psicologia, por terem aplicação prática, possibilitando o conhecimento da dinâmica do sujeito, seus recursos e fragilidades.

A utilização da Técnica Projetiva Gráfica do Desenho da Família é indicada para a investigação das representações das experiências de apego, pois possibilita a compreensão da dinâmica familiar e sua inter-relação com a vida de seus membros. De acordo com Ackerman (1986), as experiências da vida familiar cotidiana "constroem ou destroem" a saúde mental, sendo o grupo familiar aquele que executa a tarefa primordial de socializar a criança, moldando o desenvolvimento de sua personalidade, determinando assim, em grande parte, o seu destino mental.

\section{MÉTODO}

- Sujeito:

No período de setembro a dezembro de 2001, participou deste estudo um paciente do sexo feminino diagnosticada como apresentando Transtorno Depressivo Maior, segundo os critérios do Manual Diagnóstico e Estatístico de Transtornos Mentais (DSM-IV, 1995).

\section{- Instrumentos:}

Para a realização do estudo, foi utilizado um roteiro de entrevista, elaborado por Souza (2001), contendo os seguintes tópicos:

- Encaminhamento: aborda dados referentes a tratamentos realizados (anteriores e atuais), profissionais responsáveis, tempo de tratamento, bem como de onde e por quem foi encaminhado, entre outros.

- Ficha de Identificação: aborda dados sociodemográficos do paciente e de seu grupo familiar, tais como sexo, idade, estado civil, renda, condições de moradia, escolaridade, profissão, etc.

- Dados Clínicos: aborda dados acerca da queixa principal e história da doença atual.

- Anamnese Padronizada para Transtornos Depressivos: baseada nos critérios diagnósticos do Manual Diagnóstico e Estatístico de Transtornos Mentais (1995).

- História de Vida: aborda aspectos descritivos e psicodinâmicos da história pré-natal, primeira infância, infância intermediária, final da infância e adolescência, vida adulta e vida cotidiana.

- Modalidades de Apego: aborda dados acerca dos vínculos estabelecidos entre o paciente e seu grupo familiar. 
Além do roteiro de entrevista, foram utilizados:

- Desenho da Família: possibilita o conhecimento da dinâmica do sujeito, seus recursos, fragilidades e as características de seu grupo.

- Roteiro de entrevista acerca dos vínculos, de Azevedo \& Souza (2002): aborda dados acerca do desenho da família, objetivando investigar as relações estabelecidas entre os membros da família e as modalidades de apego.

- Escala de Freqüência de Sinais Específicos, de Kaplan e Main apud Cecconello \& Koller (1999): composta por 24 itens que descrevem características do desenho, tais como falta de individuação, rigidez nos braços, exagero na cabeça, falta de cor, etc., que são pontuados de acordo com a sua freqüência.

- Escala Global, de Fury, Carson \& Aroufe apud Cecconello \& Koller (1999): composta por 8 sub-escalas (Vitalidade, Felicidade, Vulnerabilidade, Isolamento, Tensão, Papéis Invertidos, Dissociação e Patologia Global), nas quais a pontuação pode variar de sete (7) a um (1): muito alto, alto, moderadamente alto, moderado, moderadamente baixo, baixo, e muito baixo.

\section{- Procedimentos:}

Inicialmente o plano de estudo foi submetido ao Comitê de Ética em Pesquisa. Quanto à seleção do paciente, a mesma foi realizada pelo médico psiquiatra que atendia o caso, respeitando-se os critérios de inclusão no estudo, ou seja, apresentar, segundo os critérios do Manual Diagnóstico e Estatístico de Transtornos Mentais (DSM-IV), Transtorno Depressivo Maior, não apresentar comorbidade com outros transtornos, ser maior de idade, não haver constituído família e aceitar a presença do pesquisador em seu domicílio. Quando do início do estudo, a paciente foi solicitada a assinar o Termo de Consentimento Livre e Esclarecido, assegurando-se do sigilo de sua identidade quando da publicação dos resultados.
A aplicação dos instrumentos de pesquisa foi realizada em oito (08) encontros, com duração média de 1 hora cada, realizados no domicílio do paciente. As entrevistas foram gravadas em fitas microcassete, para posterior transcrição.

A avaliação do Desenho da Família, utilizando a Escala de Sinais Específicos e a Escala Global, foi feita por quatro (04) juízes. Após a avaliação particular de cada juiz, foram apresentados os resultados obtidos e indicada a média geral.

\section{RESULTADOS}

\section{- Identificação:}

Ana (nome fictício), sexo feminino, 29 anos de idade, solteira, cursa o Ensino Superior. É a filha mais velha de uma prole de 03 filhos, sendo a única do sexo feminino.

\section{- História da Doença Atual:}

A paciente relatou que desde a infância era uma criança triste. Informou que, no final de sua adolescência, já apresentava muitos dos sintomas depressivos, os quais se agravaram em sua vida adulta. Entre os sintomas apresentados por Ana, destaca-se o humor deprimido e irritado, diminuição do interesse e prazer na maioria das atividades, insônia, sentimento de inutilidade, culpa excessiva e inadequada, entre outros.

Ana relatou ter pensado e planejado suicídio com arma de fogo por diversas vezes, mas sua mãe sempre escondia a arma. Em seu relato: "Eu queria ser imperceptível para todo mundo, que ninguém me visse, eu não queria chamar atenção".

Diversas limitações ocorreram na vida de Ana. Algumas foram associadas aos sintomas depressivos. Destacamos quatro áreas principais: profissional, familiar, sexual e afetiva/social.

$\mathrm{Na}$ área profissional, a paciente relatou que não consegue permanecer no emprego/ 
estágio, em função de sintomas que apresenta, uma vez que, por diversas vezes, teve crises durante o expediente de trabalho. Naárea familiar, relatou vivenciar diversos conflitos, destacando a difícil convivência com sua mãe. Na área sexual, destacou apresentar dificuldades associadas aos sintomas depressivos. Quanto à área afetiva e social, relatou evitação social, em que seus relacionamentos são caracterizados como "superficiais".

Com relação aos tratamentos realizados, a paciente destacou que, aos 21 anos de idade recebeu acompanhamento psicológico, contudo, após um ano, o tratamento foi interrompido, pois não dispunha de recursos para financiá-lo. Vale destacar que a paciente mantinha o tratamento psicológico em segredo, pois sua mãe era contrária a tal tratamento.

No final do ano de 2000, aos 28 anos de idade, com o incentivo do namorado, buscou ajuda em um serviço municipal de atendimento à família, sendo encaminhada ao Ambulatório de Ansiedade e Depressão (AMBAD).

Ana iniciou tratamento psiquiátrico e psicológico no AMBAD no início do ano de 2002. Atualmente, realiza apenas tratamento psiquiátrico e faz uso de um psicofármaco (Cloridrato de Paroxetina/ Inibidor Seletivo da Recaptação de Serotonina).

A paciente relatou também apresentar rinite, gastrite e alergia.

\section{- História de Vida:}

A paciente destacou que seu nascimento foi indesejado. Segundo Ana, sua mãe veio do interior do Estado do Pará para morar na capital, na casa de uma família, objetivando prosseguir os estudos. Sua mãe engravidou de um dos membros dessa família, sendo obrigada a casar.

Informou que nasceu de parto normal, não apresentando nenhum problema por ocasião do nascimento. Ressaltou que, nos primeiros dias de sua vida, foi cuidada pela avó paterna, uma vez que "sua mãe era inexperiente". A mesma considera sua avó paterna como a figura mais importante de seus primeiros dias de vida.

Quanto à primeira infância (0 a 3 anos), Ana relatou que foi amamentada até seis meses, usou chupeta até 8 anos e dedo até 16 anos. Não soube informar quando começou a falar, nem a andar, destacando que começou a freqüentar a escola aos 2 anos e meio de idade. Relatou que, nesse período, sua mãe e a avó paterna disputavam a função de cuidar dela, o que gerava um clima de tensão.

Segundo a paciente, ela era o centro das atenções até o nascimento de seu irmão. Seus familiares desejavam uma criança do sexo masculino e, quando seu irmão nasceu um ano depaois, Ana sentiu-se "esquecida e abandonada".

Com relação a sua infância intermediária (3a 11 anos), destacou que começou a freqüentar a escola aos 2 anos e meio, assim como seus irmãos, pois seus pais trabalhavam fora de casa. Considera "um crime" ter começado a freqüentar a escola nessa idade, mas relatou que gostava de ir à escola, não apresentando dificuldades em nenhuma disciplina, e tendo aprovação em todas as séries correspondentes a essa fase.

Nesse período, participava de todas as atividades da escola, como jogos e festas. Destacou que gostava de brincar na rua, tendo várias amigas. Relatou que seu temperamento era calmo e que buscava não se envolver em brigas e discussões. Informou apresentar insônia e sonambulismo e dificuldades relacionadas à saúde, como gastrite e anemia.

Relatou que, nesse período, foi cuidada por sua mãe e sua avó paterna, destacando que seus pais, ela e os irmãos moraram na casa da avó até seus nove anos de idade. Nessa casa, moravam também outros parentes, entre os quais outras crianças. Enfatizou que, como era a neta mais velha, era muito solicitada para cuidar dos irmãos e dos primos, motivo pelo qual brincava mais com crianças da rua.

Destacou que sua mãe era muito exigente quanto à educação e, apesar de não participar, 
"queria bons resultados". Quanto ao seu pai, relatou que era "ausente, mas rígido", não admitindo que os filhos errassem. Quando isso ocorria, impunha castigos físicos.

Negou ter sofrido perdas significativas, destacando: "Nunca fui de sentir falta". Quanto a separações, destacou que não ficou abalada com a separação de seus pais, uma vez que o pai sempre foi ausente.

Acerca do final de sua infância e adolescência (12 a 18 anos), destacou que aos 12 anos foi morar no interior do Pará, juntamente com seus pais e irmãos. A paciente relatou não se ter adaptado à mudança e ter adoecido gravemente de estomatite e complicações na garganta.

Segundo Ana, nessa fase, seus pais separaram-se, permanecendo no interior, a mãe, ela e os irmãos. Aos 14 anos mudou-se para a casa da avó, em Belém, objetivando cursar o Ensino Médio. Nesse período, relatou ter apresentado dificuldades de adaptação na nova escola, sendo reprovada na $1^{\text {a }}$ série do Ensino Médio.

Após um ano morando com a avó, sua mãe e seus irmãos retornaram a Belém e todos passaram a residir em outro domicílio. Sua mãe havia iniciado um relacionamento com outro homem, o qual veio para Belém em companhia da família. A paciente destacou ter uma relação conflituosa com o padrasto. Este a assediava, o que ocasionou conflitos entre ela e sua mãe, pois a última não acreditava no que a filha relatava acerca do companheiro.

Na adolescência, não usou álcool, drogas ou cigarro. Quanto a seus hábitos alimentares, costumava comer em excesso, tendendo à obesidade. Destacou ainda que, nesse período, passou a ser responsável pelas tarefas domésticas, deixando de desenvolver atividades de lazer.

Ingressou na universidade aos 18 anos, optando por fazer o mesmo curso e seguir a mesma profissão dos pais. Quanto à escolha profissional, refere-se à influência de sua mãe, que ofereceu um bem, caso fizesse o mesmo curso que ela. Informou, também, que foi reprovada no primeiro ano da faculdade e, que, no quarto ano, abandonou o curso por dois anos. Atualmente, retornou à faculdade.

Durante o curso, passou a fazer estágios remunerados, sendo que permanecia nos mesmos por apenas aproximadamente um mês, pois sentia que o trabalho exigia muito dela, além de apresentar dificuldades de relacionamento com os colegas de trabalho.

Com referência à sociabilidade, relatou ter facilidade em "lidar com pessoas", contudo, "evita estreitar vínculos de amizade", não sendo comum ter conversas íntimas, sair junto, freqüentar a casa, ou mesmo telefonar para colegas, uma vez que considera "que amigos dão trabalho e preocupação". Em suas palavras: "Eu tenho facilidade em lidar com as pessoas, mas eu não crio laços, eu não estreito laços".

No que diz respeito a sua sexualidade, relatou apresentar diversas dificuldades na área sexual, entre elas vaginismo e frigidez.

Sua relação com o companheiro atual já dura três anos, destacando que "ele é a pessoa em quem mais confio", como relata: "Para mim ele é um apoio, é a pessoa que eu mais confio, porque foi a primeira pessoa que se interessou pelos meus problemas, que procurou solução". Destacou, entre as qualidades do companheiro, as seguintes: "inteligência", "cavalheirismo", "sensibilidade", "dedicação", "esforço", entre outras.

Quanto ao relacionamento com familiares, relatou estar sempre em conflito, principalmente com a mãe. Atribui essa relação conflituosa aos problemas que teve com o companheiro da mãe, o que nos dias atuais ainda é motivo de discussão entre as duas.

Acerca da vida cotidiana, destacou que suas atividades restringiam-se a freqüentar a faculdade e encontrar com o namorado diariamente.

Informou que evita contato com os familiares, ficando geralmente trancada em seu 
quarto. Esse comportamento também é comum para os demais membros de sua família. Em suas palavras: "É cada um na sua, cada um aqui em casa tem o seu quarto, tem tudo para não discutir. Nós somos totalmente individualistas". Segundo Ana, um dia em família "é conflituoso", pois quando estão reunidos, sempre ocorrem discussões, motivo pelo qual procuram manterse isolados.

\section{- Modalidades de Apego:}

Foi possível identificar o estabelecimento da relação de apego ansiosa e evitante com figuras de vinculação. Ana respondeu afirmativamente para determinadas situações e negativamente para outras situações, que correspondiam ou não a sua condição, como especificado abaixo:

\section{Apego Ansioso Evitante (A.A.E.)}

\section{a) Esperava ser rejeitado e abandonado pelas pessoas que cuidaram de mim.}

A paciente negou tal condição, uma vez que considerava que sua mãe e sua avó não a rejeitariam ou a abandonariam, pois foram educadas para criar filhos e cuidar da casa. Vale destacar que Ana descreveu o abandono sofrido em relação ao seu pai.

"A minha mãe e a minha avó sempre estiveram disponíveis, agora o meu pai sempre foi muito ausente, o resto da família sempre foi muito ausente".

b) Meus pais ou as pessoas que cuidaram de mim não estiveram disponíveis, oferecendo cuidados e ajuda necessários ao meu desenvolvimento.

A paciente identificou-se com essa afirmação, destacando que essa situação correspondia a sua condição na infância, uma vez que sua mãe e avó eram muito ocupadas, não lhe dando atenção necessária.

"A minha mãe estudava e trabalhava, era muito ausente (...)".
“(...) então uma criança, elas não pensam se amam ou se não amam, elas tem a obrigação de cuidar, foi essa a educação que elas tiveram".

c) Não tinha confiança de quando buscasse ajuda seria ajudado.

A paciente negou tal situação em sua infância. Contudo, foi possível identificar, em seu relato, que procurou viver independentemente. Em suas palavras:

"Aqui em casa, cada cabeça é uma sentença, um é totalmente diferente do outro, porque na realidade é assim, eu tenho a ciente conclusão de que nós não fomos educados, nós nos educamos, a gente sempre ficou de mão em mão".

d) Procurei viver a minha vida sem amor e sem a ajuda dos outros.

A paciente negou tal situação em sua infância. Contudo, relatou que buscava fazer suas atividades sem a ajuda dos outros, pois vivia num ambiente conflituoso. Destacou ainda que evitava, e ainda evita, se apegar às pessoas, pois receia ser abandonada.

"Eu não sou apegada a ninguém, eu acho que eu sempre fui assim. Eu era criança, eu acho que eu poderia me apegar a minha mãe e a minha avó, com mais ninguém, porque eu não me apego com ninguém".

"Eu não sei se é defesa minha, porque eu já tive muitos problemas, mas eu procuro não me apegar a ninguém".

\section{- Desenho da Família}

A paciente indicou que as figuras do desenho da família correspondiam a sua mãe, a ela, a seus irmãos e a um sobrinho, omitindo a figura do pai. Destaca-se que a não apresentação do desenho da família, nesta seção, deve-se a uma solicitação explícita de Ana, para a não divulgação do desenho.

A análise do desenho, por meio da Escala de Freqüência de Sinais Específicos, revelou a presença dos seguintes sinais ansiosos: três (3) 
sinais ansiosos ou evitantes (falta de individuação - figuras muito semelhantes, braços para baixo, e falta de cor); cinco (5) sinais ansiosos ou inseguros (falta de detalhes nas figuras, figuras flutuando -sem base nos pés, figuras incompletas - braços pela metade, homens e mulheres não diferenciados - muito semelhantes, expressão facial neutra); dois (2) sinais ansiosos e resistentes (exagero nas feições faciais, exagero nas mãos e nos braços). (Tabela 01)

Não foram encontrados os seguintes sinais: sinais ansiosos ou evitantes: mãe e criança longe na página, omissão da mãe ou da criança, exagero no tamanho da cabeça, membros ocultos, escondidos ou disfarçados; sinais ansiosos ou inseguros: mãe não feminizada; sinais ansiosos ou resistentes: figuras aglomeradas ou sobrepostas, figuras separadas por barreiras, figuras muito pequenas, figuras muito grandes, exagero nas articulações, figuras no canto da página; sinais desorganizados ou desorientados: inícios falsos, figuras esmagadas, cenas, sinais ou símbolos bizarros.

Com referência à análise do desenho da Família de Origem, por meio da Escala Global, as subescalas apresentaram as seguintes pontuações: Vitalidade (Muito baixo - 7); Felicidade (Muito baixo - 7); Vulnerabilidade (Muito Alto - 1); Isolamento (Muito Alto - 1); Tensão (Muito alto - 1); Papéis Invertidos (Baixo - 6); Dissociação (Moderadamente baixo - 5); e Patologia Global (Muito alto - 1). (Tabela 02)

Tabela 1. Freqüência dos Sinais Específicos de Desenho da Família de Origem.

\begin{tabular}{ll}
\hline a) Sinais Ansiosos ou Evitantes & Família de Origem \\
\hline - Falta de individuação & 1 \\
- Braços para baixo ou próximo ao corpo & 1 \\
- Falta de cor & 1 \\
TOTAL & $\mathbf{3}$ \\
b) Sinais Ansiosos ou Inseguros & \\
- Falta de detalhes & 1 \\
- Figuras flutuando & 1 \\
- Figuras incompletas & 1 \\
- Homens e mulheres não diferenciados & 1 \\
- Expressão facial neutra ou negativa & 1 \\
TOTAL & $\mathbf{1}$ \\
c) Sinais Ansiosos ou Resistentes & $\mathbf{5}$ \\
- Exagero nas feições faciais & \\
-Exagero nas mãos e nos braços & $\mathbf{2}$ \\
\hline TOTAL & 1 \\
\hline
\end{tabular}


Tabela 2. Pontuação na Escola Global do Desenho da Família de Origem.

\begin{tabular}{lc}
\hline Sub-escolas & Família de Origem \\
\hline Vitalidade & Muito baixo (7) \\
Felicidade & Muito baixo (7) \\
Vulnerabilidade & Muito alto (1) \\
Isolamento & Muito alto (1) \\
Tensão & Muito alto (1) \\
Papéis Invertidos & Baixo (6) \\
Dissociação & Moderadamente (5) \\
Patologia Global & Muito alto (7) \\
\hline
\end{tabular}

\section{DISCUSSÃO}

O presente estudo sugere a presença de uma representação mental da relação de apego ansiosa, considerando-se o estabelecimento de vínculos afetivos disfuncionais em sua família de origem (pais e irmãos).

A história da doença atual revelou um elevado sofrimento individual. Segundo Ana, suas atividades cotidianas ficaram limitadas, comprometendo sua qualidade de vida. Segundo Silva (1990), a depressão altera a capacidade do indivíduo de funcionar adequadamente, prejudicando seu relacionamento com os outros. De acordo com este autor, essa alteração é evidenciada de várias formas, entre elas a na vida profissional, pois o indivíduo tem baixo rendimento, podendo ser obrigado a deixar o emprego, que implica uma dependência dos familiares para mantê-lo, ocasionando conflitos, uma vez que tais familiares geralmente não entendem seu estado de desânimo, desinteresse e apatia, o que agrava o quadro apresentado.

Silva (1990) destaca, ainda, que a depressão resulta de uma combinação de fatores biológicos e psicossociais, incluindo bioquímicos, genéticos, neuroendócrinos, da saúde em geral, familiares, da personalidade, sociais, assim como os acontecimentos de vida, tais como: separação ou morte de pessoas significativas, nova moradia ou trabalho, séria doença pessoal ou de um membro da família, entre outros.

A paciente indicou a ocorrência de diversos eventos vitais estressantes, os quais podem estar associados à ocorrência do transtorno de humor.

Em sua infância, Ana destacou inúmeros conflitos em seu ambiente familiar, caracterizado por brigas e discussões entre seus pais, que culminou na separação conjugal. De acordo com Soares (1998), a família tem um papel determinante no desenvolvimento da sociabilidade e do bem estar físico dos indivíduos, principalmente no período da infância e adolescência. Para este autor, quem vive num ambiente caracterizado por tensão e brigas com os pais, agredindo-se, pode futuramente encontrar dificuldade concreta para relaxar e gozar.

O período da adolescência também foi caracterizado pela ocorrência de eventos estressores. Nesse período, ela e seus familiares mudaram de cidade e sua mãe uniu-se a outro companheiro, com o qual Ana tinha muitas dificuldades de relacionamento.

Desiderio apud Assumpção Jr. \& Sprovieri (1995) afirmam que o estabelecimento de vínculos disfuncionais e a distorção de regras familiares junto com a sociedade, na qual se inspira, podem ocasionar desajustamento psicoemocional de uma ou mais pessoas da família.

Em sua vida adulta, Ana relatou dificuldade em estabelecer vínculos afetivos, destacando evitar contato com as pessoas, inclusive seus familiares. Segundo Bowlby (1988), o afastamento do contato com outros indivíduos tem como objetivo evitar maiores frustrações e, também, evitar a intensa depressão que experimentam por odiarem as pessoas de que tanto necessitam. Assim, o retraimento é uma alternativa que alguns indivíduos encontram para fugir dessa situação. 
O relato livre da paciente e o desenho da família sugerem o estabelecimento de uma relação de apego ansioso e evitante com figuras significativas (pai, mãe, avó) da infância. Observamos que esse modelo persiste, uma vez que a paciente evita vincular-se a outras pessoas, o que pode estar associado ao medo de ser rejeitada.

Bowlby (1998) afirma que crianças que sofrem rejeição ou abandono tendem a representar um modelo de si mesmas, como uma pessoa indigna de ser amada, e de um modelo de suas figuras de apego, como sendo inacessíveis, rejeitadoras e punitivas. Dessa forma, quando uma pessoa sofre uma adversidade não acredita que os outros podem ajudá-la, ao contrário, espera deles hostilidade e rejeição, desenvolvendo uma modalidade de apego ansioso evitante.

Ressalta esse autor que, na maioria das manifestações dos distúrbios depressivos, a principal questão do paciente é o sentimento de desamparo quanto a sua capacidade de estabelecer e manter relações afetivas. Tal sentimento de desamparo pode ser atribuído às experiências vividas pelo paciente em sua família de origem, que podem ser de três tipos correlatos ou da combinação deles, descritos a seguir:

“a) É provável que a pessoa tenha passado pela experiência amarga de nunca ter estabelecido uma relação estável e segura com seus pais (...). Essas experiências infantis fazem com que ela desenvolva uma acentuada tendência de interpretar qualquer perda que possa sofrer mais tarde como mais um de seus fracassos em estabelecer e manter uma relação afetiva estável;

b) É provável que, muitas vezes, tenham dito à pessoa que ela era indigna de ser amada e/ou inconveniente, e/ou incompetente. Se passou por essas experiências, estas provavelmente resultaram no desenvolvimento de um modelo de si mesma como uma pessoa indigna de ser amada, indesejada, e de um modelo de figuras de apego como sendo inacessíveis, ou rejeitadoras e punitivas; c) Para esta pessoa é maior do que para as outras a probabilidade de ter sofrido a perda real de um dos pais durante a infância (...)." (Bowlby, 1998, p. 259-260).

Consideramos-a partir da análise dos dados coletados, principalmente aquelas referentes às características do vínculo estabelecido por Ana em relação ao pesquisador, o qual também se revelou ansioso e evitante, -que a relação de apego ansioso e evitante, estabelecida entre Ana e suas figuras significativas, durante a infância e adolescência, tenha contribuído para a manifestação do transtorno depressivo já na sua adolescência, agravado na sua fase adulta.

A utilização da técnica projetiva gráfica do Desenho da Família foi relevante para a compreensão das relações familiares. Segundo Gomes (1999), essa técnica possibilita o acesso à ótica interiorizada, no indivíduo, acerca de suas relações familiares, o que permite comparação e complemento aos dados fornecidos pela anamnese realizada anteriormente.

De acordo com Cecconello \& Koller (1999), uma das grandes vantagens que o Desenho da Família apresenta, em relação a outros instrumentos que se propõem a avaliar a representação mental, é a possibilidade de mensuração, por meio de um recurso gráfico com a utilização de escalas. Outro fator é que tal recurso viabiliza a comunicação, poupando verbalizações de situações que podem ser ansiogênicas.

A avaliação do desenho da família, por intermédio da Escala de Sinais Específicos, revelou uma freqüência considerável de sinais ansiosos, enquanto que a Escala Global revelou uma Patologia Global muito alta das relações de apego estabelecidas na família da paciente.

Os relatos e a avaliação do desenho da família indicaram experiências de apego com figuras significativas como ansiosas. De acordo com Bowlby, apud Cecconello et al. (2000), as experiências de apego funcionam como modelo para os próximos relacionamentos, sendo tal processo denominado modelo interno de 
funcionamento, o qual evolui, passando a fazer parte da personalidade, transformando-se em uma representação mental da relação de apego, que tende a persistir por toda a vida.

Um estudo realizado por Main \& Kaplan, apud Pontes et al. (1999), classificou padrões de apego em adultos, entre estes: adultos autônomos, adultos indiferentes e adultos preocupados. Os autônomos são indivíduos que valorizam suas experiências e relações de apego e conseguem examinar com tranqüilidade os efeitos positivos e negativos de suas experiências primitivas sobre seu desenvolvimento. Os indiferentes geralmente afirmam não poder lembrar de suas primeiras experiências e as consideram sem valor. Quando solicitados a descrever sua história pessoal, apresentam relatos idealizados das suas primeiras experiências, embora apresentem histórias de rejeição precoce. Os preocupados são confusos, em relação as suas experiências familiares, lembrando-se das suas primeiras experiências, mas não conseguindo apresentar um relato coerente. Em geral, suas relações atuais são marcadas por intenso sentimento de raiva, além de extrema dependência das figuras paternas.

No caso em estudo, sugere-se a presença de um padrão de apego indiferente, uma vez que a mesma não recordava algumas de suas experiências infantis, idealizando esse período, descrevendo-se como a "princesa da casa", por se a única filha do sexo feminino. Contudo, apresentava histórias de rejeição precoce, destacando não ter recebido os cuidados necessários para o seu desenvolvimento.

A família é considerada como um espaço de expressão de seus membros, exercendo funções fundamentais para o desenvolvimento dos mesmos, principalmente no período da infância, quando há maior dependência. Segundo CHESS \& HASSIBI (1982), a família tem um papel importante no desenvolvimento de seus membros. Estes autores ressaltam a relevância de um ambiente afetivo que atenda às necessidades da criança, oferecendo-lhe estimulação cognitiva, motora e perceptiva adequada, preparando-a para uma relação emocional com outras pessoas, de forma a capacitá-la a desempenhar papéis sociais.

Foi possível indicar, também, o estabelecimento de vínculos afetivos, tendendo para a disfuncionalidade no grupo familiar da paciente, uma vez que este espaço não se configurou como facilitador de saúde mental, o que pode ter contribuído para as manifestações patológicas do transtorno que apresenta.

\section{CONSIDERAÇÕES FINAIS}

A realização do presente estudo revelou o comprometimento das atividades globais da paciente investigada, associado à sintomatologia do transtorno depressivo. Tal realidade leva-nos a refletir acerca da importância da prevenção e intervenção precoce, como também sobre a necessidade de que quadros psiquiátricos sejam minimizados em suas conseqüências físicas, psicológicas, sociais, entre outras.

A utilização das escalas para a avaliação do desenho da família revelou-se adequada, uma vez que forneceu dados importantes para a compreensão da dinâmica de sua família. Além disso, a técnica de desenho da família é de simples aplicação, não exigindo grande ônus para isso.

Concluímos, destacando a importância da família, na promoção de saúde biopsicossocial e na construção do sujeito, ressaltando a Teoria do Apego e dos Vínculos Humanos, a qual enfatiza o papel do grupo familiar enquanto base segura.

\section{REFERÊNCIAS BIBLIOGRÁFICAS}

ACKERMAN, N. W. (1986). Diagnóstico e Tratamento das Relações Familiares. Porto Alegre: Artes Médicas.

ANZIEU, D. (1978). Os Métodos Projetivos. Rio de Janeiro: Campus. 
ASSUMPÇÃO Jr., F.B. \& Sprovieri, M.H. (1995). Contexto Sócio-Familiar e Eventos Vitais Significativos na Evolução das Doenças Mentais. Insight, Ano V. No 53, p. 23-27, julho.

AZEVEDO, C.M. \& SOUZA, A.M. Desenho da Família: Um Estudo de Caso da Representação Mental da Relação de Apego em Pacientes que Apresentam Transtorno Ansioso e em Pacientes que Apresentam Transtorno Depressivo. XIII Seminário de Iniciação Científica da Universidade Federal do Pará. Belém/PA, 2002.

BOWLBY, J. (1988). Cuidados Maternos e Saúde Mental (2 ed). São Paulo: Martins Fontes.

BOWLBY, J. (1998). Perda: Tristeza e Depressão (3 ed). Vol. 3 da Trilogia Apego e Perda. São Paulo: Martins Fontes.

BOWLBY, J. (1989). Uma Base Segura: Aplicações Clínicas da Teoria do Apego. Porto Alegre: Artes Médicas.

CECCONELLO, A. M. \& Koller, S. M. (1999). Avaliação da Representação Mental da Relação de Apego Através do Desenho da Família: Um Estudo com Crianças Brasileiras. Arquivos Brasileiros de Psicologia. Rio de Janeiro: Imago Editora, Vol. 51, № 4, 1999, pp. 39-51.

CECCONELLO, A. M.; Krum, F.M.B. \& Koller, S.M. (2000). Indicadores de Risco e Proteção no Relacionamento Mãe-criança e Apego. Psico. Porto Alegre, Vol. 31, № 2 Jul/Dez, pp. 81-121.
CHESS, S. \& Hassibi, M. (1982). Princípios e Práticas da Psiquiatria Infantil. Porto Alegre: Artes Médicas.

GOMES, I.C. (1999). O Uso de Técnicas Projetivas no Processo Psicodiagnóstico Infantil como Auxiliares no Entendimento do Sintoma da Criança e no Encaminhamento. Perfil . No 12. São Paulo, p. 89-97.

MANUAL DIAGNÓSTICO EESTATÍSTICO DE TRANSTORNOS MENTAIS-DSM IV. $4^{\mathrm{a}}$ Ed. Porto Alegre: Artes Médicas, 1995.

PONTES, F.A.R.; Dubois, M.J.C. \& Silva, S.S.C.(1999). Relação Mãe-Criança e Desenvolvimento. Humanitas. Belém, v. 15. № 2, p. 181-192, jul./dez.

SILVA, J.A.C. (1990). Acontecimentos de Vida e Depressão. Informação Psiquiátrica. V. 9. № 2, p.59-72.

SOARES, L.S.C. (1998). Doença x Família: Um Enfoque Psicossomático. Insight. Ano VII, $n^{\circ} 82$, março.

SOUZA, A. M. (2001). Pânico, Agorafobia e Ansiedade de Separação: O Revelar do Comportamento de Apego. Tese de Doutorado apresentada à Faculdade de Ciências Médicas da Universidade Estadual de Campinas-UNICAMP.

Recebido para publicação em 29 de outubro de 2002 e aceito em 4 de junho de 2003. 